\section{Thank you but not goodbye}

Six years have passed since I became Editor-in-Chief after Barrie Margetts, the first Editor-in-Chief of this journal. It has been a very interesting time; I have learnt a lot and learn every day about author ownership, ethics in relation to authorship, open access and impact factors. The new Editor-in-Chief is Dr Marilyn Tseng, from California Polytechnic, where her main interest is health and nutrition in immigrant populations. She has been on the editorial board since 2003, the last couple of years as Deputy Editor, and a very capable one, I might add. From the first issue of 2013, I will be Deputy Editor together with Dr Irja Haapala from the University of Eastern Finland and Dr Allison Hodge from the University of Melbourne. The editor-inchief and the deputies have for a few years been jointly planning each issue in advance, selecting hot topics and writing editorials together.

Running journals is an important part of academic development. The quality of our journal is very much dependent on our authors submitting high-quality papers, and on our deputy editors, associate editors and reviewers spending their precious leisure time reviewing papers and preparing the final product. The electronic system for submission and all the technical work involved in preparing the journal is done with professional backup from The Nutrition Society and Cambridge University Press.

A big thank you to all of you: authors, reviewers, editors and staff, for this year's work and all the work you have put into the journal during my period as Editorin-Chief. I am convinced that you will continue to do a great job in the future.

Season's greetings!

Agneta Yngve

Editor-in-Chief 2007-2012

(soon to be Deputy Editor) 